\title{
The use of intravenous versus subcutaneous monoclonal antibodies in the treatment of severe asthma: a review
}

\author{
Andrea Matucci ${ }^{*}$, Alessandra Vultaggio ${ }^{1}$ and Romano Danesi ${ }^{2}$
}

\begin{abstract}
Background: Monoclonal antibodies (mAbs) approved for use as add-on therapy in patients with severe asthma target the underlying pathogenesis of asthma.

Main body: Omalizumab binds immunoglobulin $\mathrm{E}(\mathrm{lg} E)$, thereby inhibiting its interaction with the high-affinity $\lg \mathrm{E}$ receptor and reducing the quantity of free IgE available to trigger the allergic cascade. Anti-interleukin (IL)-5 mAbs mepolizumab, benralizumab and reslizumab block the interaction between IL-5 and its receptor on eosinophils, thus targeting the eosinophilic pathway in asthma. Most mAbs are available as intravenous (IV) or subcutaneous (SC) formulations, as their high molecular weight and gastric degradation preclude oral administration. This review compares the pharmacology, efficacy, immunogenicity, injection- and infusion-related adverse drug reactions of subcutaneously administered omalizumab and mepolizumab with the intravenously administered reslizumab. In terms of pharmacokinetics, IV route of administration appears to be superior to the SC route due to quicker absorption, greater bioavailability, shorter time to maximum serum concentration and similar elimination half-life. Route of administration does not appear to translate into striking differences in efficacy and safety of mAbs used for the treatment of severe asthma, as all are generally considered to be effective and well tolerated. Hypersensitivity and administration-related reactions have been described with both IV and SC mAbs.

Conclusion: $\mathrm{mABs}$ are effective and have low immunogenicity due to their nature as humanised antibodies. Evidence on the use of mAbs in indications other than severe asthma suggest that both the SC and the IV routes of administrations have their respective advantages and disadvantages; but their full utility remains to be elucidated.
\end{abstract}

Keywords: Eosinophil, Mepolizumab, Monoclonal antibodies, Omalizumab, Reslizumab, Severe asthma

\section{Background}

Asthma is an inflammatory chronic disease of multifactorial aetiology, including allergic asthma, which is characterized by eosinophilic airway inflammation [1], often sustained by allergic sensitisation. Asthma is typically associated with bronchial hyper-responsiveness to direct and indirect triggers [1]. Severe asthma is defined as asthma that requires high-dose inhaled corticosteroids (ICS) plus a second controller (usually a long-acting $\beta_{2}$ agonist [LABA]) and/or systemic corticosteroids for adequate control, or which is uncontrolled despite this

\footnotetext{
* Correspondence: andrea.matucci@unifi.it

${ }^{1}$ Immunoallergology Unit, AOU Careggi, University of Florence, Largo

Brambilla 3, 50134 Florence, Italy

Full list of author information is available at the end of the article
}

high-intensity treatment [2]. An estimated $5-10 \%$ of all patients with asthma are believed to have severe refractory asthma [3].

For patients with severe uncontrolled asthma, four monoclonal antibodies (mAbs) against immunoglobulin $\mathrm{E}$ (IgE) or interleukin (IL)-5 are available for clinical use by either subcutaneous (SC) or intravenous (IV) administration as an add-on to ICS plus LABA therapy. The anti-IgE antibody omalizumab has been available for SC use in the USA since 2003 [4], and has also been approved in Europe since 2009 [5]. The anti-IL-5 antibodies mepolizumab and benralizumab for SC administration and reslizumab for IV administration were approved in 2015, 2017 and 2016, respectively, in both the USA [6-8] and Europe [9-11].

(C) The Author(s). 2018 Open Access This article is distributed under the terms of the Creative Commons Attribution 4.0 International License (http://creativecommons.org/licenses/by/4.0/), which permits unrestricted use, distribution, and reproduction in any medium, provided you give appropriate credit to the original author(s) and the source, provide a link to the Creative Commons license, and indicate if changes were made. The Creative Commons Public Domain Dedication waiver (http://creativecommons.org/publicdomain/zero/1.0/) applies to the data made available in this article, unless otherwise stated. 
According to the Global Initiative for Asthma (GINA) 2017 guidelines, add-on therapy with omalizumab should be considered in patients aged $\geq 6$ years with severe allergic asthma, while mepolizumab and reslizumab may be beneficial in patients with severe eosinophilic asthma aged $\geq 12$ years [1]. However, it is important to note that reslizumab has only been approved for adults ( $\geq 18$ years) [9].

This review provides an overview of the available IV and SC mAbs for use in patients with severe asthma and discusses the potential advantages and disadvantages associated with these routes of administration for mAbs.

\section{Pharmacokinetics}

mAbs are made of two identical heavy and light chains held together by disulphide bonds at the hinge region to form a Y-shaped structure [12]. They were first created as mouse mAbs using hybridoma technology, but to minimise the immunogenic mouse components, murine mAbs were replaced by chimeric, humanised and then fully human mAbs [13].

The pharmacokinetics (PK) of mAbs is characterised by low distribution to the extravascular compartment, because of their large molecular size and long elimination half-life $\left(t_{1 / 2}\right)$, which depends on slow intracellular catabolism, with no urinary excretion [12, 14].

The most common route of administration of mAbs is IV, followed by SC administration, although intramuscular injection is also possible [12]. Oral administration is precluded because of their large molecular size and gastrointestinal degradation [14]. The rate and extent of absorption varies between mAbs and between individuals for the same mAb [12]. For mAbs administered via the SC route, absorption into the systemic circulation first requires convective transport of the $\mathrm{mAb}$ through the interstitial space into the lymphatic system [12]. In addition, lymphatic fluid flow is slow compared with blood, thus absorption of mAbs after SC administration is a slow process, with average time to peak concentration $\left(\mathrm{T}_{\max }\right)$ of $6-8$ days [12].

In addition, PK parameters may be influenced by patient-specific factors. For example, most mAbs are administered on the basis of body weight, which is often reported to be a significant factor influencing the volume of distribution $\left(\mathrm{V}_{\mathrm{d}}\right)$ and/or systemic clearance $\left(\mathrm{CL}_{\mathrm{s}}\right)$, although this is not true for every mAb [14].

The route of administration of mAbs influences their peak serum concentration $\left(\mathrm{C}_{\max }\right)$, and this may influence the time to clinical response [15]. The first available $\mathrm{mAb}$ for asthma, omalizumab, was administered via the SC route [4], but in later clinical trials with anti-IL-5 mAbs, IV administration was used. Overall, $\mathrm{T}_{\max }$ is longer with SC than IV administration (Table 1), but SC administration allows for the maintenance of more stable levels of the biological agent during the dosing interval. Following SC administration, PK profiles are approximately linear for omalizumab (at doses $>0.5 \mathrm{mg} / \mathrm{kg}$ ) [4, 5] and mepolizumab (at doses $12.5-250 \mathrm{mg}$ ) $[7,10]$. SC administration of omalizumab or mepolizumab is associated with $\mathrm{T}_{\max }$ of up to 8 days after a single dose [4, 5 , $7,10]$. In contrast, $C_{\max }$ is rapidly reached after IV administration of mepolizumab or reslizumab, generally occurring at the end of the infusion (Table 1) $[6,9,16]$. After IV reslizumab, serum concentrations typically show a biphasic decrease after $C_{\max }[6,9]$ and $P K$ is dose-proportional at doses of $0.3-3.0 \mathrm{mg} / \mathrm{kg}$ [9].

Comparisons of the influence of route of administration on PK for mAbs approved for other disease indications also suggest broadly similar distribution and elimination with IV versus SC administration. In patients with follicular lymphoma, SC administration of the anti-CD20 antibody rituximab was shown to have non-inferior PK (meeting the prespecified $C_{\text {trough }} 90 \%$ confidence interval $[\mathrm{CI}]$ lower limit of 0.8 ) to IV rituximab [17] and similar efficacy and tolerability [18]. SC trastuzumab for human epidermal growth factor receptor 2 (HER2)-positive breast cancer had non-inferior PK (meeting the prespecified margin for the difference between groups in $C_{\text {trough }}$ of 0.8 ) and efficacy (meeting the prespecified margin for the difference between groups in pathological complete remission of $-12.5 \%)$, compared with IV administration, in a phase III, randomised, open-label trial in patients with early HER2-positive breast cancer [19].

SC treatment is usually given as a fixed dose, as is the case for mepolizumab $[7,10]$, while IV reslizumab dose varies based on the patient's body weight $[6,9]$. Indeed,

Table 1 Summary of pharmacokinetic profiles for omalizumab [4,5], mepolizumab [7, 10, 16] and reslizumab [6,9]

\begin{tabular}{lllll}
\hline & Omalizumab & Mepolizumab & & Reslizumab \\
\hline Route & $\mathrm{SC}$ & $\mathrm{SC}$ & $\mathrm{IV}$ & IV \\
Absolute bioavailability & $100 \%$ & $100 \%$ & - & - \\
$\mathrm{T}_{\max }$ & $7-8$ days & $4-8$ days & End of infusion & End of infusion \\
$V_{\mathrm{d}}$ & $78 \mathrm{~mL} / \mathrm{kg}$ & $51 \mathrm{~mL} / \mathrm{kg}$ & $55-85 \mathrm{~mL} / \mathrm{kg}$ & $\approx 5 \mathrm{~L}$ \\
$\mathrm{CL}_{\mathrm{s}}$ & $2.4 \mathrm{~mL} / \mathrm{kg} /$ day & $3.1 \mathrm{~mL} / \mathrm{kg} /$ day & $1.9-3.3 \mathrm{~mL} / \mathrm{kg} /$ day & $\approx 7 \mathrm{~mL} / \mathrm{hour}$ \\
$\mathrm{t}_{1 / 2}$ & 26 days & $16-22$ days & $\approx 20$ days & $\approx 24$ days \\
\hline
\end{tabular}

$C L_{s}$ systemic clearance, $I V$ intravenous, $P K$ pharmacokinetics, $S C$ subcutaneous, $t_{1 / 2}$ elimination half-life, $T_{\max }$ time to $C_{\max } V_{d}$ volume of distribution 
in a reslizumab population PK model, heavier body weight was associated with more rapid $\mathrm{CL}_{\mathrm{s}}$ and a larger $\mathrm{V}_{\mathrm{d}}$, supporting the appropriateness of the recommended weight-based dosing ( $3 \mathrm{mg} / \mathrm{kg}$ ), which produces comparable exposure across the entire range of weights [20]. Modelling of body weight-based dosing using data pooled from eight reslizumab clinical trials showed that steady-state reslizumab exposure after IV administration, including area under the drug concentration-time curve (AUC), $C_{\max }$ and average serum concentration $\left(C_{a v g}\right)$, remained consistent across a wide range of patient body weights [21]. Thus, weight-based IV regimens of reslizumab represent an approach that is appropriate for individual patient's requirements.

\section{Clinical efficacy}

The availability of biological agents has changed the treatment strategies for severe asthma. Initially, the availability of omalizumab changed the treatment of asthma related to IgE-mediated allergic pathogenesis, and more recently, the availability of drugs targeting IL-5, which is a fundamental factor in the differentiation, activation and survival of eosinophils, changed the treatment strategy for the eosinophilic phenotype [22]. Efficacy results for these three mAbs in severe allergic asthma have been widely confirmed by various clinical trials (Table 2) and, at least for omalizumab, have been available for over ten years, including from real-world studies [23, 24]. Their clinical efficacy represents their capacity to interfere in the pathogenic mechanisms of the disease, albeit in different ways (IL-5 vs IgE).

\section{Omalizumab}

Omalizumab is a humanised IgG1 mAb. Omalizumab selectively binds to IgE, inhibiting its interaction with the high-affinity IgE receptor (Fc epsilon $\mathrm{R}$ [FceRI]) on the surface of basophils and mast cells, reducing the quantity of free IgE available to trigger the allergic cascade $[4,5]$. In patients with allergic asthma, SC omalizumab for 24 weeks was associated with an $89-99 \%$ reduction in serum free IgE levels $[25,26]$. Importantly, other cells such as dendritic cells (DC) express FceRI [27], and can use this pathway to capture allergens. FceRI/IgE-dependent allergen presentation may therefore critically lower the atopic individual's threshold for an allergen-specific T-cell response [28]. In this connection, the therapeutic potential of anti-IgE mAbs is related to significant reductions in $\mathrm{CD} 4^{+}$ and $\mathrm{CD}^{+} \mathrm{T}$ lymphocytes and B lymphocyte counts and central cytokine IL-4 production [29], which are involved in the pathogenesis of bronchial asthma. Furthermore, randomised controlled studies of patients with severe asthma have shown improved disease control with SC omalizumab and have also allowed for significant reductions in daily ICS requirements (Table 2 ) $[25,26,30]$.

\section{Anti-IL-5 antibodies}

The therapeutic effect of mepolizumab, benralizumab and reslizumab is related to their capacity to bind with high affinity to IL-5 (dissociation constants in vitro of 100 and $81 \mathrm{pmol} / \mathrm{L}$, respectively) and thus to block the interaction between IL-5 and its receptor on the surface of eosinophils [6, 7].

Mepolizumab Mepolizumab is an IgG1 kappa mAb. In patients with asthma and blood eosinophil counts $>300$ cells $/ \mu \mathrm{L}$, dose- and time-dependent decreases in blood eosinophil counts were observed with IV mepolizumab $75 \mathrm{mg}$ and SC mepolizumab 125 or $250 \mathrm{mg}$ administration [16]. However, authors concluded that the route of administration did not affect the drug exposure-response relationship [16]. Furthermore, given that the reduction in blood eosinophils was evident as soon as three days from administration of the drug, whether SC or IV [16], there appears to be little significant difference in the PK-pharmacodynamic profile between the two routes of administration.

The biological effects of SC mepolizumab have translated into clinical therapeutic efficacy. SC mepolizumab was associated with a significant corticosteroid-sparing effect in patients with severe eosinophilic asthma who required daily oral corticosteroids for asthma control in the SIRIUS study [31]. The MENSA clinical trial results suggested an advantage of the SC over the IV formulation. In fact, the rate of exacerbations was reduced by $47 \%$ among patients receiving IV mepolizumab and by $53 \%$ among those receiving SC mepolizumab. In addition, emergency visits or hospitalisations were reduced by $32 \%$ and $61 \%$ in the group receiving IV and SC mepolizumab, respectively. The improvement in the Asthma Control Questionnaire-5 (ACQ-5) score was 0.42 points and 0.44 points greater in the two mepolizumab groups, respectively, than in the placebo group [32]. SC mepolizumab was also associated with an improvement in health-related quality of life, with the results of the phase IIIb MUSCA demonstrating significant improvements in St George's Respiratory Questionnaire scores with SC mepolizumab versus placebo after 24 weeks of treatment [33].

Benralizumab Benralizumab is a humanised, afucosylated, monoclonal antibody (IgG1, kappa) that directly binds to the alpha subunit of the human interleukin-5 receptor (IL-5R $\alpha)$. The IL-5 receptor is expressed on the surface of eosinophils and basophils. In an in vitro setting, the absence of fucose in the Fc domain of benralizumab facilitates binding to FC gamma $\mathrm{R}$ (FcyRIII) receptors on immune effectors cells, such as natural killer (NK) cells, leading to apoptosis of eosinophils and basophils through antibody-dependent cell-mediated 
Table 2 Main clinical outcomes from RCTs of omalizumab, mepolizumab and reslizumab in patients with severe asthma

\begin{tabular}{|c|c|c|}
\hline $\begin{array}{l}\text { First author, } \\
\text { year (study } \\
\text { name) }\end{array}$ & Patients & Study treatment \\
\hline \multicolumn{3}{|l|}{ Omalizumab } \\
\hline $\begin{array}{l}\text { Busse, } \\
2001[25]\end{array}$ & $\begin{array}{l}\text { Severe allergic asthma requiring daily ICS } \\
(n=525)\end{array}$ & $\begin{array}{l}\text { SC omalizumab q2w or q4w } \\
\text { vs PBO for } 28 \text { wks }\end{array}$ \\
\hline $\begin{array}{l}\text { Solèr, } \\
2001[26]\end{array}$ & $\begin{array}{l}\text { Symptomatic allergic asthma on daily ICS } \\
(n=546)\end{array}$ & $\begin{array}{l}\text { SC omalizumab q2w or q4w } \\
\text { vs PBO for } 28 \text { wks }\end{array}$ \\
\hline $\begin{array}{l}\text { Holgate, } \\
2014[30]\end{array}$ & Severe allergic asthma on ICS $(n=246)$ & $\begin{array}{l}\text { SC omalizumab q2w or q4w } \\
\text { vs PBO for } 32 \text { wks }\end{array}$ \\
\hline \multicolumn{3}{|l|}{ Mepolizumab } \\
\hline $\begin{array}{l}\text { Pavord, } \\
2014 \\
\text { (DREAM) } \\
{[67]}\end{array}$ & Severe eosinophilic asthma $(n=621)$ & $\begin{array}{l}\text { IV mepolizumab } 75,250 \text { or } \\
750 \text { mg q4w vs PBO for } 13 \\
\text { doses }\end{array}$ \\
\hline $\begin{array}{l}\text { Ortega, } 2014 \\
\text { (MENSA) [32] }\end{array}$ & $\begin{array}{l}\text { Severe eosinophilic asthma on high-dose } \\
\text { ICS }(n=576)\end{array}$ & $\begin{array}{l}\text { IV mepolizumab } 75 \mathrm{mg} \mathrm{q} 4 \mathrm{w} \\
\text { or SC mepolizumab } 100 \mathrm{mg} \\
\text { q4W vs PBO for } 32 \mathrm{wks}\end{array}$ \\
\hline
\end{tabular}

Main clinical outcomes q4w vs PBO for 32 wks Significantly fewer asthma exacerbations per patient vs
PBO with stable ICSs $(0.28$ vs $0.54 ; p=0.006)$ and during
ICS reduction ( 0.39 vs $0.66 ; p=0.004)$

Significantly fewer asthma exacerbations per patient vs PBO with stable ICSs $(0.28$ vs $0.66 ; p<0.001)$ and during ICS reduction (0.36 vs $0.75 ; p<0.001)$

Significantly greater median reductions in ICS dose vs PBO (60\% vs 50\%; $p=0.003)$; $\geq 50 \%$ ICS dose reduction achieved by $73.8 \%$ vs $50.8 \%$ of patients ( $p=0.001$ )

Fewer clinically significant exacerbations per patient-year vs PBO $(1.15-1.46$ vs $2.40 ; p<0.001)$

Significantly decreased rate of exacerbations with IV (by $47 \%)$ and SC (by 53\%) mepolizumab vs PBO $(p<0.001)$; significantly greater mean increases in $\mathrm{FEV}_{1}$ with IV (by $100 \mathrm{~mL}$ ) and SC (by $98 \mathrm{~mL})$ vs PBO $(p<0.05)$; significantly decreased rate of exacerbations needing hospitalisation with SC mepolizumab vs PBO (by $61 \% ; p$ $=0.02$ )

SC mepolizumab $100 \mathrm{mg} \mathrm{q4W}$ Significantly greater likelihood of reducing systemic vs PBO for 20 wks corticosteroid dose vs PBO (OR 2.39; 95\% Cl 1.25-4.56; $p$ $=0.008$ ); significantly greater median dose reduction vs PBO (50\% vs 0\%; $p=0.007)$; significantly lower rate of exacerbations per year vs PBO (1.44 vs 2.12; $p=0.04$ )

(SIRIUS) corticosteroids $(n=135)$

[31]

Severe eosinophilic asthma on high-dose ICS $(n=274)$

SC mepolizumab $100 \mathrm{mg}$ q4W vs PBO for 24 weeks

Significantly improved SGRQ total score vs PBO (LSM change from baseline-15.6 vs $-7.9 ; p<0.0001$ )

(MUSCA)

[33]

Reslizumab

Castro,

2015 [37]

Inadequately controlled asthma with

IV reslizumab $3.0 \mathrm{mg} / \mathrm{kg}$ q4w $\geq 400 / \mu \mathrm{L}$ blood eosinophils ( $n=953$ in two vs PBO for 52 wks duplicate studies)

Bjermer, Inadequately controlled asthma with

2016 [38] $\geq 400 / \mu \mathrm{L}$ blood eosinophils $(n=315)$
IV reslizumab 0.3 or $3.0 \mathrm{mg} / \mathrm{kg}$ q4w vs PBO for 16 wks
Significantly reduced rate of exacerbations vs PBO (study 1 RR 0.50; $95 \%$ Cl 0.37-0.67; study 2 RR 0.41; $95 \%$ Cl $0.28-0.59$; both $p<0.001$ ); significantly greater increases in $\mathrm{FEV}_{1}$ VS PBO (study 1 RR $0.126 ; 95 \% \mathrm{Cl} 0.06-0.188 ; \mathrm{p}<$ 0.0001 ; study 2 RR 0.090; $95 \% \mathrm{Cl} 0.003-0.153 ; p=0.0057$ ); significantly improved scores on the ACQ and AQLQ vs PBO (study 1 both $p<0.001$; study $2 p<0.001$ and $p<$ 0.01 , respectively)

Significant greater increases in $\mathrm{FEV}_{1}$ with $0.3 \mathrm{mg} / \mathrm{kg}$ (by $115 \mathrm{~mL}$ ) and $3.0 \mathrm{mg} / \mathrm{kg}$ (by $160 \mathrm{~mL}$ ) vs PBO (both $p<$ $0.05)$; significantly improved scores on the ACQ and AQLQ VS PBO $(p<0.05)$

ACQ Asthma Control Questionnaire, AQLQ Asthma Quality of Life Questionnaire, $C$ confidence interval, FEV ${ }_{1}$ forced expiratory volume over $1 \mathrm{~s}, I C S$ inhaled corticosteroids, IV intravenous, LSM least squares mean, OR odds ratio, PBO placebo, $q 2 w$ every 2 weeks, $q 4 w$ every 4 weeks, $R C T$ randomised controlled trial, $R R$ rate ratio, SC subcutaneous, SGRQ St George's Respiratory Questionnaire

cytotoxicity (ADCC). Benralizumab is indicated as an add-on maintenance treatment in adult patients with severe eosinophilic asthma inadequately controlled despite high-dose ICS plus LABA. Benralizumab is administered at the dose of $30 \mathrm{mg}$ by $\mathrm{SC}$ injection given every 4 weeks for the first 3 doses, then every 8 weeks. In patients with an eosinophil count of $\geq 300$ cells $/ \mu \mathrm{L}$, significant improvements in lung function, as defined by forced expiratory volume over $1 \mathrm{~s}\left(\mathrm{FEV}_{1}\right)$, were observed. At the end of treatment, benralizumab patients had a $24 \%$ improvement from mean baseline in $\mathrm{FEV}_{1}$ of $1.66 \mathrm{~L}$. In addition, studies also showed greater improvements in $\mathrm{FEV}_{1}$ in patients with higher baseline blood eosinophil counts and more frequent prior exacerbation history [34]. Interestingly, patients receiving benralizumab achieved greater reductions in daily maintenance oral corticosteroid dose, while maintaining asthma control [35]. 
Reslizumab Reslizumab is an IgG4 kappa mAb. The biological activity of reslizumab has been described in patients with severe persistent asthma treated with high-dose ICS or oral corticosteroids, in which a single dose of IV reslizumab 0.3 or $1 \mathrm{mg} / \mathrm{kg}$ reduced peripheral eosinophil counts from baseline in a dose-dependent manner after $48 \mathrm{~h}$ [36]. Compared with placebo, the decrease in blood eosinophil counts with reslizumab $1 \mathrm{mg} /$ $\mathrm{kg}$ remained significant up to day 30 after administration $(p=0.05$ vs placebo) [36].

These biological effects correspond with clinical results for asthma control with IV reslizumab. In patients with inadequately controlled asthma and elevated blood eosinophil levels $(\geq 400$ cells $/ \mu \mathrm{L})$, IV reslizumab $3.0 \mathrm{mg} /$ $\mathrm{kg}$ every 4 weeks was associated with a significant reduction in the frequency of asthma exacerbations, as well as significant improvements in $\mathrm{FEV}_{1}$, asthma quality of life (AQLQ) and ACQ-7 scores, in two identically designed phase III studies [37]. In another phase III study, which evaluated reslizumab 0.3 and $3 \mathrm{mg} / \mathrm{kg}$ every 4 weeks, both doses were associated with significant improvements in $\mathrm{FEV}_{1}$ and ACQ scores, as well as reductions short acting $\beta$-agonist use [38]. Reslizumab has consistently reduced blood eosinophil concentrations in phase III studies [37, 38].

Several post hoc analyses have been conducted to identify the subgroups of traditionally difficult-to-treat patients who may respond to reslizumab treatment. These groups include patients with chronic sinusitis and nasal polyps, asthma severity corresponding to step 4 and 5 of the GINA classification, oral corticosteroid-dependent patients and those aged $\geq 65$ years $[37,39,40]$. In addition, post hoc analyses of phase III clinical trials indicate that patients who experience $\mathrm{FEV}_{1}$ response $(\geq 100 \mathrm{ml})$ and/or ACQ response within the first 16 weeks have greater improvements in the clinical asthma exacerbation rate that those who do not [41]. Furthermore, an algorithm that takes into account the $\mathrm{FEV}_{1}, \mathrm{ACQ}$, asthma quality of life and clinical asthma exacerbation rate at baseline and at week 16 has been developed to predict early response to reslizumab and help guide treatment decisions [42].

Overall, the main clinical outcomes from the key clinical studies of omalizumab, mepolizumab and reslizumab are summarised in Table 2. These data indicate that mAbs are effective in the treatment of severe asthma. While most outcomes appear to be similarly improved by drugs with SC and IV route of administration, it should be noted that IV reslizumab has been associated with improvement in $\mathrm{FEV}_{1}$, ACQ-7 and Asthma Symptom Utility Index (ASUI) at first assessment, which occurred 4 weeks after treatment initiation [37]. On the other hand, no mAb administered subcutaneously has been shown to have such rapid effects. Relatively slow absorption and lower bioavailability of SC mAbs fits well with the current knowledge of the mechanisms underlying their distribution, namely reliance on the lymphatic system.

\section{Immunogenicity}

Biological agents have the potential to induce an immune response leading to the production of specific anti-drug antibodies (ADAs). ADAs are particularly relevant when they neutralise the drug $[43,44]$, because they bind directly to the active site of the $\mathrm{mAb}$, eliminating the interaction between the drug and its target and, therefore, reducing the clinical therapeutic effect [45]. Potential clinical consequences of immunogenicity range from little or no effect (as discussed below) to altered PK or efficacy, as well as induction of hypersensitivity reactions [45]. Infusion reactions have also been linked to the formation of drug-ADA complexes [46].

\section{Immunogenicity in severe asthma}

In comparison with the immunogenicity of the mAbs for rheumatoid arthritis adalimumab and infliximab (mentioned earlier), mAbs used for severe asthma appear to present less of a problem. Humanised mAbs such as omalizumab, mepolizumab and reslizumab, are mostly derived from human Ig sequences, with only the complementarity-determining regions being of murine Ig origin [12]. There were no cases of anti-omalizumab antibody development with SC omalizumab administration in patients with severe allergic asthma $[25,26,30$, 47]. During mepolizumab treatment in the MENSA trial, anti-mepolizumab antibodies were detected in $4 \%$ of patients with IV administration, 5\% with SC administration and $2 \%$ with placebo; neutralising antibodies were not detected [32]. In SIRIUS, anti-mepolizumab antibodies were detected in six patients overall $(4 \%)$, with one patient developing neutralising antibodies after the first dose of SC mepolizumab; however, serious adverse events relating to immunogenicity were not reported [31]. A much greater difference in immunogenicity between the SC and IV formulations of mepolizumab has been observed; in a study using a modified ADA assay where a mepolizumab competitive anti-IL-5 antibody was added in a pre-treatment step, the ADA rate for IV and SC mepolizumab was $1 \%$ and $8 \%$, respectively [48]. This supports previous data cited in this review suggesting greater immunogenicity of SC formulations; however, as mentioned, many factors influence the development of immunogenicity, and assay method may also result in variation in observations of immunogenicity [46].

In an analysis of pooled data from all four phase III placebo-controlled reslizumab studies in patients with asthma, 5\% (53/938) of reslizumab $3 \mathrm{mg} / \mathrm{kg}$ recipients had anti-reslizumab antibodies, but readings were of low titre 
and frequently transient [9]. The same ADA rate was found in an open-label extension study of patients with asthma receiving IV reslizumab $3 \mathrm{mg} / \mathrm{kg}$ for up to 36 months (5\% [49/1014]) [9]. Among patients positive for treatment-emergent anti-reslizumab antibodies, the reduction in blood eosinophil levels was similar to that observed in patients negative for anti-reslizumab antibodies, suggesting that these antibodies were not neutralising [38]. Anti-reslizumab antibodies were not associated with hypersensitivity reactions and had no effect of the clinical pharmacodynamics or PK of reslizumab [9].

While data suggest the possibility of an immunogenic response to anti-IL-5 mAbs, the potential clinical implications in patients with asthma are not yet firmly established.

\section{Factors influencing immunogenicity}

Many factors influence the development of immunogenicity: drug dose, administration route, but also concomitant medications, underlying disease and the drug structure [46]. Immunogenicity of mAbs depends, at least in part, on the fraction of nonhuman sequence in the drug molecule [12]. Immunogenicity is lower with more humanised mAbs compared with chimeric mAbs [46]. Infliximab, a chimeric $\mathrm{mAb}$ that is administered intravenously, is associated with the formation of ADA in up to $50 \%$ of patients with rheumatoid arthritis, while even the humanised mAb adalimumab, which is administered subcutaneously, induces ADA in a significant proportions of these patients (12-37\%) [46]. Nevertheless, mAbs are generally well tolerated in humans, despite containing sequences that may be recognised by the recipient as non-self epitopes and can stimulate an immune response [13].

In fact, immunogenicity appears to be associated not only with route of administration, but also with drug dose [49] and duration of therapy [12]. For example, higher doses of the tumour necrosis factor (TNF)- $\alpha$ blocker infliximab - corresponding to higher serum drug levels - appeared to be linked to lower immunogenicity and greater duration of effect [50]. In a study of 101 patients with active rheumatoid arthritis, ADAs formed in 53\%, 21\% and 7\% of patients receiving infliximab 1,3 and $10 \mathrm{mg} / \mathrm{kg}$, respectively [50]. The reasons for this inverse relationship between mAb dose and immune response are yet to be elucidated [12]. Longer treatment duration may be associated with an increased opportunity for an immune response [12].

\section{Immunogenicity in other indications}

Studies in mice have indicated that the strength of an immune response towards the biological agent may be dependent on the route of administration [51, 52]. Generally, SC administration of anti-TNF- $\alpha$ mAbs is more immunogenic than IV administration, due to the smaller volumes used, slower drug distribution and greater variability in inter-individual drug exposure, leading to increased formation of ADAs. Another reason for greater immunogenicity of the SC route could be the fact that skin is highly specialised for processing foreign antigens [15]. Other mAb classes for which data exist comparing the immunogenicity of IV versus SC formulations include tocilizumab (IL-6 blocker) [53], trastuzumab (HER2 antagonist) [54], and rituximab (B-cell inhibitor). A meta-analysis of data from 8974 patients in 14 studies (five SC tocilizumab and nine IV tocilizumab) reported a low and similar risk of immunogenicity with the SC and IV formulations, with the proportion of patients with ADAs being $1.5 \%$ versus $1.2 \%$, respectively [53]. In contrast, more SC recipients than IV recipients who developed ADAs were also positive for the neutralising assay (85.1\% vs $78.3 \%)$, although presence of neutralising ADAs did not appear to result in loss of therapeutic efficacy of either formulation [53]. ADA formation was greater with SC trastuzumab than with IV trastuzumab in a phase III trial in 596 patients with early breast cancer comparing these formulations (14.6\% vs $7.1 \%)$, although authors concluded there was no apparent significant relationship between ADA formation and efficacy or safety [54]. Finally, in the SABRINA phase III trial comparing SC vs. IV rituximab in 410 patients with follicular lymphoma, the rate of ADA formation was low and similar between groups (2\% vs $1 \%)$ [18]. Importantly, the SC formulation of rituximab used in the SABRINA trial is a novel formulation designed to enable delivery of therapeutic doses at acceptable volumes of administration by using a 12 times more concentrated dose and including a recombinant human hyaluronidase in the formulation to enhance drug dispersion and absorption by temporarily hydrolysing hyaluronic acid fibres in the interstitial matrix [18], thereby overcoming the PK limitations of SC administration.

\section{Differences in immunogenicity between SC and IV administration}

Compared with IV administration, SC injection of large molecules such as mAbs is thought to increase the risk of immunogenicity via DC processing [45]. DCs are present in greater numbers at the cutaneous and subcutaneous layers of the skin, and are therefore located in an ideal position to capture the drug, process it and then migrate to lymph nodes, where they can act as antigen-presenting cells for autologous $\mathrm{T}$ cells, giving rise to the immune response [55]. In addition to migratory DCs, SC drugs may be subjected to a second round of antigen presentation by lymph node-resident DCs [56], thus producing a generally stronger immune response than IV drugs. 


\section{Infusion reactions}

The adverse effects characteristic of mAbs relate to the body's immune response to the drug. This response may range from being a minor, transient, subclinical reaction to a serious, potentially fatal, reaction when the immune system overreacts (hypersensitivity) [57]. Infusion-related reactions to mAbs are typically mediated via ADA immune complexes [46], and may be local or systemic, the latter being more frequent, though less severe and typical of drugs administered via SC route. In patients treated with infliximab, ADAs were mostly represented by members of the IgG class [58]; however, multiple classes (IgM, IgE, IgG) and sub-classes (IgG1-4) can be produced during humoral anti-drug response [59]. In patients who experienced severe reactions to infliximab, the presence of specific circulating IgE antibodies and positive skin test to infliximab have been reported $[59,60]$. In general, SC administration may be associated with localised injection-site reactions, including hypersensitivity, tenderness, warmth and redness [61], whereas both SC and IV administration may cause systemic reactions [57].

Adverse reactions highlighted in the prescribing information for the anti-IL5 mAbs mepolizumab and reslizumab and the anti-IgE mAb omalizumab include such hypersensitivity reactions and administration-related reactions $[5,9,10]$, although differences in their tolerability profiles may be observed based on their immunogenicity and route of administration. For example, in patients with severe allergic asthma, local injection-site symptoms were more common with SC omalizumab ( $n=$ $274)$ than with placebo $(n=272)$ in one study $(11.8 \%$ vs $7.7 \%)$; omalizumab was more frequently associated with redness, warmth and itching symptoms [26]. Most of these adverse events were of mild severity. Similar results were reported in another placebo-controlled trial of SC omalizumab in 246 patients with severe allergic asthma: most injection-site reactions were mild and transient and were reported in $20.4 \%$ of omalizumab recipients versus $10.3 \%$ of placebo recipients [30]. Severe injection-site reactions occurred with a similar incidence in both groups [30]. In a third study, authors concluded that the tolerability profile of SC omalizumab was broadly similar to that of placebo [25]. It seems overall that the problem of injection-site reactions appears to be limited for SC omalizumab.

SC mepolizumab appears to be similarly well tolerated. In the SIRIUS study in 135 patients with severe eosinophilic asthma, local injection-site reactions occurred in only four patients $(6 \%)$ on SC mepolizumab $100 \mathrm{mg}$ and two (3\%) on placebo [31]. Four mepolizumab and three placebo recipients experienced systemic reactions (severity unspecified) [31]. One patient experienced serious type IV delayed hypersensitivity to mepolizumab, which required hospitalisation [62].

The greater frequency of injection-site reactions with the $\mathrm{SC}$ route versus the IV route was confirmed in the only head-to-head comparison to date of IV versus SC administration of monoclonal antibodies in patients with severe asthma (the MENSA trial) [32]. In this randomised, double-blind, double-dummy study in 576 patients with severe eosinophilic asthma, injection-site reactions were reported more often with SC mepolizumab $100 \mathrm{mg}$ (9\% of patients) than with IV mepolizumab $75 \mathrm{mg}$ or placebo (3\% for both) [32]. IV reslizumab appears to be better tolerated than IV mepolizumab with regard to injection-site reactions, with the same proportion of patients receiving reslizumab $3.0 \mathrm{mg} / \mathrm{kg}$ and placebo ( $2 \%$ of patients) experiencing administration site reactions in a pooled analysis of four phase III studies. None of the administration site reactions/events were severe, serious or resulted in discontinuation [9].

Although serious infusion reactions are a rare event for biological agents used in asthma, in three studies of patients with inadequately controlled asthma and elevated eosinophil levels, IV reslizumab was associated with anaphylactic reactions in three ADA-negative patients, who responded to standard treatment and were withdrawn from the studies [37, 63].

Treatment with biological agents, specifically mAbs, is associated with the formation of circulating immunocomplexes, leading to the activation of the complement system. Activation of $\mathrm{C} 1$ fraction occurs at significant levels only when it binds to the $\mathrm{CH} 2$ domains of IgG molecules. Furthermore, only certain subclasses of IgG are effective complement activators and exert this activity in human IgG1, but not IgG4. Regarding mAbs used in asthmatic patients, it is important to underline that reslizumab is an IgG4 and that it does not activate the complement system.

Besides drug efficacy and tolerability, the rational choice of $\mathrm{mAb}$ and route of administration is also influenced by patient preference, pharmacoeconomic considerations and other factors, as discussed below.

\section{Patient preference, pharmacoeconomics and other considerations}

In general, selecting the appropriate route of administration should be driven by efficacy and safety, as well as cost effectiveness and patient preference, as this will ensure optimal treatment adherence [64].

As discussed previously, mAbs are often administered by the IV route, which provides maximum bioavailability with minimal risk of immunogenicity. In addition, IV administration is suitable for medications that are administered in large volumes and those that may cause irritation [65]. The drawbacks of IV administration include the fact that it often requires dedicated personnel, which likely makes it less convenient and, if performed at a hospital, more expensive [45]. 
SC administration is less invasive than IV administration, it may be performed by the patient and therefore, is associated with shorter clinic visits and more optimised use of healthcare resources $[45,65]$. On the other hand, disadvantages of SC administration include slower absorption and lower bioavailability than IV, as well as higher probability of injection-site reactions and pain associated with administration of large fluid volumes [65].

As highlighted in a recent systematic review (encompassing any drug class and indication), there are limited data on these various factors influencing choice of injection route [64]. Thus, data for mAbs that are well-established therapeutic options in inflammatory diseases such as rheumatoid arthritis and oncology are included here.

In an observational study of 201 patients with rheumatoid arthritis who were receiving treatment with IV infusions when asked if they would switch to SC administration, patients $(54.2 \%)$ who chose to switch from IV to SC administration found SC injections more convenient than continuing IV therapy [66].

Studies examining patient preference and/or adherence to IV or SC formulations of mAbs for severe asthma are required to further aid clinicians in determining the optimal drug and route of administration for their patients.

\section{Discussion}

Of the three mAbs that are available as add-on therapy in patients with severe asthma, IV and SC routes of administration may be utilised: reslizumab for the former and mepolizumab, benralizumab and omalizumab for the latter. Route of administration influences their pharmacology, but this does not appear to translate into striking differences in efficacy and safety, with all three drugs considered efficacious and generally well tolerated.

One of the main effects of route of administration on drug PK profile is on absorption, which is slower after SC dosing compared with IV dosing [12]. Higher clinical variability between subjects was observed following SC administration compared with the IV route, which might reflect this difference in the absorption process [15]. As may be expected, the $T_{\max }$ of IV reslizumab is much shorter than SC mepolizumab, benralizumab and omalizumab. Generally, mAbs have low $V_{d}$ and $t_{1 / 2}$ because of their large molecular size and hydrophilic nature [14], with some data suggesting a longer $t_{1 / 2}$ with IV versus SC administration of mepolizumab [16]. Therefore, form the PK standpoint, IV route of administration appears to be superior to the $\mathrm{SC}$ route due to complete bioavailability, shorter $\mathrm{T}_{\max }$ and similar $\mathrm{t}_{1 / 2}$.

In clinical studies, reslizumab, benralizumab, mepolizumab and omalizumab have been consistently found effective in the treatment of patients with severe allergic asthma, reducing the number of clinical exacerbations experienced by patients in a year. Of the different drugs, mepolizumab has been studied for both IV and SC administration. The results of the MENSA clinical trial indicate that the SC mepolizumab may have superior efficacy over the IV formulation with regard to reducing the rate of serious asthma exacerbations [32]. On the other hand, IV reslizumab has been associated with significant and consistent improvements in lung function and patient-reported outcomes within 4 weeks as well as a reduction of serious asthma exacerbations [37].

Immunogenicity is an important component of the pharmacology of mAbs. In this respect, the IV route of administration is likely to be superior, as it is associated with lower immunogenicity, as well as fewer local hypersensitivity reactions [46]. However, all the mAbs for severe asthma have a relatively low immunogenic potential because they are humanized mAbs, and data from clinical studies of SC omalizumab, benralizumab, mepolizumab and IV reslizumab suggest little or no ADA production. In the case of IV reslizumab, the ADAs were of low titre, frequently transient, with no evidence of neutralising ADAs, and were not associated with hypersensitivity reactions $[9,38]$. Pivotal clinical studies indicate that there appears to be minimal influence of ADA formation on therapeutic effect. SC omalizumab and mepolizumab and IV reslizumab are all effective in reducing asthma exacerbations in patients with the appropriate severe asthma phenotype. While hypersensitivity and administration-related reactions are characteristic of both IV and SC mAbs, SC omalizumab and mepolizumab and IV reslizumab were all generally well tolerated. In the only head-to-head comparison of IV versus SC administration of a mAb for asthma, the safety profiles of IV and SC mepolizumab were similar [32].

\section{Conclusions}

Currently available mAbs for the treatment of severe asthma include omalizumab, mepolizumab and reslizumab. These drugs are effective and have low immunogenicity due to their nature as humanised antibodies. Data collected on mAbs used in indications other than severe asthma suggest that both the SC and the IV routes of administrations have their respective advantages and disadvantages. Further research into this area is necessary.

\section{Abbreviations}

ADA: Anti-drug antibodies; AQLQ: Asthma quality of life; ASUI: Asthma Symptom Utility Index; AUC: Area under the concentration-time curve; $\mathrm{Cl}$ : Confidence interval; $\mathrm{CL}_{\text {s }}$ : Systemic clearance; $\mathrm{C}_{\text {max }}$ : Peak serum concentration; DC: Dendritic cells; FcyRIII: FC gamma R; FcERI: Fc epsilon R; $\mathrm{FEV}_{1}$ : Forced expiratory volume over $1 \mathrm{~s}$; GINA: Global Initiative for Asthma; HER2: Human epidermal growth factor receptor 2; ICS: Inhaled corticosteroid; Ig: Immunoglobulin; IL: Interleukin; iv: Intravenous; LABA: Long-acting $\beta_{2}$ agonist; mAbs: Monoclonal antibodies; OR: Odds ratio; PBO: Placebo; 
PK: Pharmacokinetics; q2w: Every 2 weeks; q4w: Every 4 weeks; RCT: Randomised controlled trial; RR: Rate ratio; SC: Subcutaneous; $\mathrm{t}_{1 / 2}$ : Halflife; $T_{\max }$ : Time to maximum plasma drug concentration; TNF: Tumour necrosis factor; $V_{d}$ : Volume of distribution

\section{Acknowledgements}

We would like to thank Sarah Greig, PhD, of Springer Healthcare Communications who wrote the outline of the manuscript and Tracy Harrison who wrote the first draft of this manuscript on behalf of Springer Healthcare Communications. This medical writing assistance was funded by Teva Pharmaceutical Industries. A review of the medical accuracy of the paper was also provided by Teva Pharmaceutical Industries.

\section{Funding}

Editorial assistance was funded by Teva Pharmaceutical Industries.

\section{Authors' contributions}

MA and AV: wrote parts of the manuscript, provided bibliographic sources, revised and approved the drafts. RD: provided bibliographic sources, revised and approved drafts. All authors read and approved the final manuscript.

\section{Ethics approval and consent to participate}

Not applicable.

\section{Consent for publication}

Not applicable.

\section{Competing interests}

$\mathrm{AM}$ and $\mathrm{AV}$ have received payment for lectures and consultant arrangements from Novartis, Glaxo-Smith-Kline, Teva, Astra-Zeneca. AM and AV have received research support from Novartis, Glaxo-Smith-Kline and Sanofi.

$\mathrm{RD}$ receives research fundings from Pfizer, Boehringher, AstraZeneca, Novartis and Celgene and honoraria from Pfizer, Boehringher, AstraZeneca, Novartis, Janssen, Roche and Celgene. The authors declare that they have no competing interests.

\section{Publisher's Note}

Springer Nature remains neutral with regard to jurisdictional claims in published maps and institutional affiliations.

\section{Author details}

${ }^{1}$ Immunoallergology Unit, AOU Careggi, University of Florence, Largo Brambilla 3, 50134 Florence, Italy. ${ }^{2}$ Clinical Pharmacology and Pharmacogenetics Unit, Department of Clinical and Experimental Medicine, University of Pisa, Pisa, Italy.

\section{Received: 14 May 2018 Accepted: 8 August 2018}

\section{Published online: 16 August 2018}

\section{References}

1. Global Initiative for Asthma. Global strategy for asthma management and prevention. 2017. http://ginasthma.org/2017-gina-report-global-strategy-forasthma-management-and-prevention.

2. Chung KF, Wenzel SE, Brozek JL, Bush A, Castro M, Sterk PJ, et al. International ERS/ATS guidelines on definition, evaluation and treatment of severe asthma. Eur Respir J. 2014:43(2):343-73.

3. American Academy of Allergy, Asthma \& Immunology. The prevalence of severe refractory asthma. 2014. http://www.aaaai.org/global/latest-researchsummaries/New-Research-from-JACl-In-Practice/refractory-asthma.

4. US Food and Drug Administration. Xolair ${ }^{\circledast}$ (omalizumab) for injection, for subcutaneous use. 2016. http://www.accessdata.fda.gov/drugsatfda_docs/ label/2016/103976s5225lbl.pdf.

5. European Medicines Agency. Xolair $75 \mathrm{mg}$ powder and solvent for solution for injection. 2016. http://www.ema.europa.eu/docs/en_GB/document_ library/EPAR - Product_Information/human/000606/WC500057298.pdf.

6. US Food and Drug Administration. Cinqair ${ }^{\circledast}$ (reslizumab) injection, for intravenous use. 2016. http://www.accessdata.fda.gov/drugsatfda_docs/ label/2016/761033lbl.pdf.
7. US Food and Drug Administration. Nucala ${ }^{\circledast}$ (mepolizumab) for injection, for subcutaneous use. 2015. http://www.accessdata.fda.gov/drugsatfda_docs/ label/2017/125526s002lbl.pdf.

8. US Food and Drug Administration. Fasenra (benralizumab) injection, for subcutaneous use. 2017. http://www.accessdata.fda.gov/drugsatfda_docs/ nda/2017/7610700rig1s000Lbl.pdf.

9. European Medicines Agency. Cinqaero $10 \mathrm{mg} / \mathrm{mL}$ concentrate for solution for infusion. 2017. http://www.ema.europa.eu/docs/en_GB/document_ library/EPAR___Product_Information/human/003912/WC500212250.pdf.

10. European Medicines Agency. Nucala $100 \mathrm{mg}$ powder for solution for injection. 2017. http://www.ema.europa.eu/docs/en_GB/document_library/ EPAR_-_Product_Information/human/003860/WC500198037.pdf.

11. European Medicines Agency. Fasenra (benralizumab) summary of opinion (initial authorisation). 2017. http://www.ema.europa.eu/docs/en_GB/ document_library/Summary_of_opinion_-_Initial_authorisation/human/ 004433/WC500238040.pdf.

12. Ryman JT, Meibohm B. Pharmacokinetics of monoclonal antibodies. CPT Pharmacometrics Syst Pharmacol. 2017;6(9):576-88.

13. Hansel $T$, Kropshofer $H$, Singer $T$, Mitchell JA, George AJ. The safety and side effects of monoclonal antibodies. Nat Rev Drug Discov. 2010;9(4):32538.

14. Keizer RJ, Huitema AD, Schellens JH, Beijnen JH. Clinical pharmacokinetics of therapeutic monoclonal antibodies. Clin Pharmacokinet. 2010;49(8):493-507.

15. Ordas I, Mould DR, Feagan BG, Sandborn WJ. Anti-TNF monoclonal antibodies in inflammatory bowel disease: pharmacokinetics-based dosing paradigms. Clin Pharmacol Ther. 2012;91(4):635-46.

16. Pouliquen IJ, Kornmann O, Barton SV, Price JA, Ortega HG. Characterization of the relationship between dose and blood eosinophil response following subcutaneous administration of mepolizumab. Int J Clin Pharmacol Ther. 2015;53(12):1015-27.

17. Salar A, Avivi I, Bittner B, Bouabdallah R, Brewster M, Catalani O, et al. Comparison of subcutaneous versus intravenous administration of rituximab as maintenance treatment for follicular lymphoma: results from a two-stage, phase IB study. J Clin Oncol. 2014:32(17):1782-91.

18. Davies A, Merli F, Mihaljevic B, Mercadal S, Siritanaratkul N, Solal-Celigny P, et al. Efficacy and safety of subcutaneous rituximab versus intravenous rituximab for first-line treatment of follicular lymphoma (SABRINA): a randomised, open-label, phase 3 trial. Lancet Haematol. 2017;4(6):e272-82.

19. Ismael G, Hegg R, Muehlbauer S, Heinzmann D, Lum B, Kim SB, et al. Subcutaneous versus intravenous administration of (neo) adjuvant trastuzumab in patients with HER2-positive, clinical stage I-III breast cancer (HannaH study): a phase 3, open-label, multicentre, randomised trial. Lancet Oncol. 2012;13(9):869-78.

20. European Medicines Agency. Cinqaero (reslizumab) Public Assessment Report. 2016. http://www.ema.europa.eu/docs/en_GB/document_library/ EPAR_-_Product_Information/human/003912/WC500212250.pdf.

21. Jaworowicz D, Fiedler-Kelly J, Rabinovich-Guilatt L, Bond M. The steady-state pharmacokinetic (PK) profile across a range of patient body weight categories supports weight-based dosing for intravenous (IV) reslizumab. Am J Respir Crit Care Med. 2016;193:A1389.

22. Kouro T, Takatsu K. IL-5- and eosinophil-mediated inflammation: from discovery to therapy. Int Immunol. 2009;21(12):1303-9.

23. Alhossan A, Lee CS, MacDonald K, Abraham I. "real-life" effectiveness studies of Omalizumab in adult patients with severe allergic asthma: meta-analysis. J Allergy Clin Immunol Pract. 2017:5(5):1362-70.

24. Brusselle G, Michils A, Louis R, Dupont L, Van de Maele B, Delobbe A, et al. "real-life" effectiveness of omalizumab in patients with severe persistent allergic asthma: the PERSIST study. Respir Med. 2009;103(11):1633-42.

25. Busse W, Corren J, Lanier BQ, McAlary M, Fowler-Taylor A, Cioppa GD, et al. Omalizumab, anti-lgE recombinant humanized monoclonal antibody, for the treatment of severe allergic asthma. J Allergy Clin Immunol. 2001;108(2): 184-90.

26. Solèr M, Matz J, Townley R, Buhl R, O'Brien J, Fox H, et al. The anti-lgE antibody omalizumab reduces exacerbations and steroid requirement in allergic asthmatics. Eur Respir J. 2001;18(2):254-61.

27. Oettgen HC. Fifty years later: emerging functions of lgE antibodies in host defense, immune regulation, and allergic diseases. J Allergy Clin Immunol. 2016;137(6):1631-45.

28. Maurer D, Ebner C, Reininger B, Fiebiger E, Kraft D, Kinet JP, et al. The high affinity lgE receptor (fc epsilon RI) mediates IgE-dependent allergen presentation. J Immunol. 1995;154(12):6285-90. 
29. Djukanovic R, Wilson SJ, Kraft M, Jarjour NN, Steel M, Chung KF, et al. Effects of treatment with anti-immunoglobulin E antibody omalizumab on airway inflammation in allergic asthma. Am J Respir Crit Care Med. 2004;170(6):583-93.

30. Holgate ST, Chuchalin AG, Hebert J, Lotvall J, Persson GB, Chung KF, et al. Efficacy and safety of a recombinant anti-immunoglobulin $E$ antibody (omalizumab) in severe allergic asthma. Clin Exp Allergy. 2004;34(4):632-8.

31. Bel EH, Wenzel SE, Thompson PJ, Prazma CM, Keene ON, Yancey SW, et al. Oral glucocorticoid-sparing effect of mepolizumab in eosinophilic asthma. N Engl J Med. 2014;371(13):1189-97.

32. Ortega HG, Liu MC, Pavord ID, Brusselle GG, FitzGerald JM, Chetta A, et al. Mepolizumab treatment in patients with severe eosinophilic asthma. N Engl J Med. 2014;371(13):1198-207.

33. Chupp GL, Bradford ES, Albers FC, Bratton DJ, Wang-Jairaj J, Nelsen LM, et al. Efficacy of mepolizumab add-on therapy on health-related quality of life and markers of asthma control in severe eosinophilic asthma (MUSCA): a randomised, double-blind, placebo-controlled, parallel-group, multicentre, phase 3b trial. Lancet Respir Med. 2017;5(5):390-400.

34. Bleecker ER, FitzGerald JM, Chanez P, Papi A, Weinstein SF, Barker P, et al. Efficacy and safety of benralizumab for patients with severe asthma uncontrolled with high-dosage inhaled corticosteroids and long-acting beta2-agonists (SIROCCO): a randomised, multicentre, placebo-controlled phase 3 trial. Lancet. 2016;388(10056):2115-27.

35. Nair P, Wenzel S, Rabe KF, Bourdin A, Lugogo NL, Kuna P, et al. Oral glucocorticoid-sparing effect of benralizumab in severe asthma. N Engl J Med. 2017;376(25):2448-58.

36. Kips JC, O'Connor BJ, Langley SJ, Woodcock A, Kerstjens HA, Postma DS, et al. Effect of SCH55700, a humanized anti-human interleukin-5 antibody, in severe persistent asthma: a pilot study. Am J Respir Crit Care Med. 2003; 167(12):1655-9.

37. Castro M, Zangrilli J, Wechsler ME, Bateman ED, Brusselle GG, Bardin P, et al. Reslizumab for inadequately controlled asthma with elevated blood eosinophil counts: results from two multicentre, parallel, double-blind, randomised, placebo-controlled, phase 3 trials. Lancet Respir Med. 2015;3(5): 355-66.

38. Bjermer L, Lemiere C, Maspero J, Weiss S, Zangrilli J, Germinaro M. Reslizumab for inadequately controlled asthma with elevated blood eosinophil levels: a randomized phase 3 study. Chest. 2016;150(4):789-98.

39. Brusselle G, Canvin J, Weiss S, Sun SX, Buhl R. Stratification of eosinophilic asthma patients treated with reslizumab and GINA Step 4 or 5 therapy. ERJ Open Res. 2017:3:3.

40. Máspero J. Reslizumab in the treatment of inadequately controlled asthma in adults and adolescents with elevated blood eosinophils: clinical trial evidence and future prospects. Ther Adv Respir Dis. 2017;11(8):311-25.

41. Bateman ED, Zangrilli J, Germinaro M, Weiss S, Castro M. Association between early improvements in lung function and asthma control with reslizumab and the annual rate of asthma exacerbations. Am J Respir Crit Care Med. 2016;193:A7782.

42. Canvin J, Noble R, Djukanovic R, Curran M, Weiss S, Torvinen S, et al. Latebreaking abstract: early identification of responders to reslizumab at 16 weeks using an algorithm derived from the pivotal clinical studies of severe eosinophilic asthma (SEA) patients. Eur Respir J. 2016:48(suppl 60):OA2998.

43. Chirmule N, Jawa V, Meibohm B. Immunogenicity to therapeutic proteins: impact on PK/PD and efficacy. AAPS J. 2012;14(2):296-302.

44. Krishna M, Nadler SG. Immunogenicity to biotherapeutics - the role of antidrug immune complexes. Front Immunol. 2016;7:1-13.

45. Smith A, Manoli H, Jaw S, Frutoz K, Epstein AL, Khawli LA, et al. Unraveling the effect of immunogenicity on the PK/PD, efficacy, and safety of therapeutic proteins. J Immunol Res 2016;2016:2342187.

46. Mok CC, Tsai WC, Chen DY, Wei JC. Immunogenicity of anti-TNF biologic agents in the treatment of rheumatoid arthritis. Expert Opin Biol Ther. 2016; 16(2):201-11.

47. Odajima H, Ebisawa M, Nagakura T, Fujisawa T, Akasawa A, Ito K, et al. Longterm safety, efficacy, pharmacokinetics and pharmacodynamics of omalizumab in children with severe uncontrolled asthma. Allergol Int. 2017; 66(1):106-15.

48. Liao K, Meyer E, Lee TN, Loercher A, Sikkema D. Inhibition of interleukin-5 induced false positive anti-drug antibody responses against mepolizumab through the use of a competitive blocking antibody. J Immunol Methods. 2017:44115-23.

49. Vincent FB, Morand EF, Murphy K, Mackay F, Mariette X, Marcelli C. Antidrug antibodies (ADAb) to tumour necrosis factor (TNF)-specific neutralising agents in chronic inflammatory diseases: a real issue, a clinical perspective. Ann Rheum Dis. 2013;72(2):165-78.

50. Maini RN, Breedveld FC, Kalden JR, Smolen JS, Davis D, Macfarlane JD, et al. Therapeutic efficacy of multiple intravenous infusions of anti-tumor necrosis factor alpha monoclonal antibody combined with low-dose weekly methotrexate in rheumatoid arthritis. Arthritis Rheum. 1998:41(9):1552-63.

51. Kijanka G, Jiskoot W, Schellekens H, Brinks V. Effect of treatment regimen on the immunogenicity of human interferon beta in immune tolerant mice. Pharm Res. 2013;30(6):1553-60

52. Mohanan D, Slutter B, Henriksen-Lacey M, Jiskoot W, Bouwstra JA, Perrie $Y$, et al. Administration routes affect the quality of immune responses: a crosssectional evaluation of particulate antigen-delivery systems. J Control Release. 2010;147(3):342-9.

53. Burmester GR, Choy E, Kivitz A, Ogata A, Bao M, Nomura A, et al. Low immunogenicity of tocilizumab in patients with rheumatoid arthritis. Ann Rheum Dis. 2017;76(6):1078-85.

54. Jackisch C, Kim SB, Semiglazov V, Melichar B, Pivot X, Hillenbach C, et al. Subcutaneous versus intravenous formulation of trastuzumab for HER2positive early breast cancer: updated results from the phase III HannaH study. Ann Oncol. 2015;26(2):320-5.

55. Haniffa M, Gunawan M, Jardine L. Human skin dendritic cells in health and disease. J Dermatol Sci. 2015;77(2):85-92.

56. Fathallah AM, Bankert RB, Balu-lyer SV. Immunogenicity of subcutaneously administered therapeutic proteins - a mechanistic perspective. AAPS J. 2013;15(4):897-900.

57. Vogel WH. Infusion reactions: diagnosis, assessment, and management. Clin J Oncol Nurs. 2010;14(2):E10-21.

58. Svenson M, Geborek P, Saxne T, Bendtzen K. Monitoring patients treated with anti-TNF-alpha biopharmaceuticals: assessing serum infliximab and anti-infliximab antibodies. Rheumatology (Oxford). 2007;46(12):1828-34.

59. Vultaggio A, Matucci A, Nencini F, Pratesi S, Parronchi P, Rossi O, et al. Antiinfliximab IgE and non-IgE antibodies and induction of infusion-related severe anaphylactic reactions. Allergy. 2010;65(5):657-61.

60. Vultaggio A, Matucci A, Nencini F, Pratesi S, Petroni G, Cammelli D, et al. Drug-specific Th2 cells and lgE antibodies in a patient with anaphylaxis to rituximab. Int Arch Allergy Immunol. 2012;159(3):321-6.

61. Hernandez MV, Sanmarti R, Canete JD, Descalzo MA, Alsina M, Carmona L, et al. Cutaneous adverse events during treatment of chronic inflammatory rheumatic conditions with tumor necrosis factor antagonists: study using the Spanish registry of adverse events of biological therapies in rheumatic diseases. Arthritis Care Res (Hoboken). 2013;65(12):2024-31.

62. European Medicines Agency. Mepolizumab summary review of regulatory action. 2015. http://www.accessdata.fda.gov/drugsatfda_docs/nda/2015/ 1255260rig1s000SumR.pdf.

63. Corren J, Weinstein S, Janka L, Zangrilli J, Garin M. Phase 3 study of reslizumab in patients with poorly controlled asthma: effects across a broad range of eosinophil counts. Chest. 2016;150(4):799-810.

64. Jin JF, Zhu LL, Chen $M, X u H M$, Wang HF, Feng XQ, et al. The optimal choice of medication administration route regarding intravenous, intramuscular, and subcutaneous injection. Patient Prefer Adherence. 2015: 9923-42.

65. Jackisch C, Muller V, Maintz C, Hell S, Ataseven B. Subcutaneous administration of monoclonal antibodies in oncology. Geburtshilfe Frauenheilkd. 2014;74(4):343-9.

66. Desplats M, Pascart $T$, Jelin G, Norberciak L, Philippe P, Houvenagel E, et al, Are abatacept and tocilizumab intravenous users willing to switch for the subcutaneous route of administration? A questionnaire-based study. Clin Rheumatol. 2017;36(6):1395-400.

67. Pavord ID, Korn S, Howarth P, Bleecker ER, Buhl R, Keene ON, et al. Mepolizumab for severe eosinophilic asthma (DREAM): a multicentre, double-blind, placebo-controlled trial. Lancet. 2012;380(9842):651-9. 